\title{
Psicopatologia em O duplo de Dostoiévski
}

\author{
Carla Fonseca Zambaldi*1
}

O duplo aborda o tema da duplicidade do eu. Traz na narrativa descrições psicopatológicas da síndrome de duplos subjetivos e da esquizofrenia numa época em que essas condições ainda não tinham sido descritas. Este artigo situa a obra literária na história da psiquiatria, ressaltando o pioneirismo de Fiodor Dostoiévski, sua forma de narrar o tema e como conseguiu tratar o tema de forma clínica.

Palavras-chave: Síndrome de falsa identificação delirante, síndrome do duplo subjetivo, esquizofrenia, literatura e medicina

\footnotetext{
${ }^{* 1}$ Universidade Federal de Pernambuco - UFPE (Recife, PE, Br).
} 
O escritor russo Fiodor Dostoiévski tem um conjunto de obras literárias marcadas por habilidosas descrições da mente humana. Seus personagens frequentemente mostram conflitos pessoais, ambivalências, indecisões, angústias existenciais ou doenças mentais. Como relata o historiador Joseph Frank, Dostoiévski mostrou ter o incomparável dom para o retrato psicológico

O livro $O$ Duplo foi publicado no início da sua vida literária e antes do seu período de prisão e trabalho forçado na Sibéria. Nessa época, prevalecia na Rússia a escola literária que valorizava os romances realísticos e que abordavam questões sociais. O primeiro livro de Dostoiévski, Gente pobre, seguiu essa tendência e foi muito elogiado pela crítica. Já o segundo, $O$ Duplo, não foi tão bem recebido. Dostoiévski tentou imprimir um estilo literário próprio nessa obra, afirmando, anos mais tarde, que nunca lançou em literatura nada mais sério. Belínki, um importante crítico russo, considerou que a obra continha "colorido fantástico", e que "em nossa época, o fantástico pode ter lugar em manicômios, mas não na literatura, pode ser assunto para médicos, mas não para poetas' (Frank, 2008, p. 235).

A obra $O$ Duplo surpreende por apresentar descrições claras e precisas de sintomas psicóticos, sendo escrito em uma época que o conceito de esquizofrenia ainda não tinha sido definido. $O$ Duplo foi publicado em 1846, e até a publicação dos trabalhos de Kahlbaum (1863) e Hecher (1871), na segunda metade do século XIX, pouco se conhecia a respeito da esquizofrenia (Iracy Doyle, 1955). Os primórdios das descrições da doença ocorreram em 1809, com a publicação da segunda edição de Traité Médico-Philosophique sur l'Alienation Mental, de Philippe Pinel, e com Observation on Madness and Melancoly, de John Haslan (Noll, 2009). Pinel (1809) descreve uma condição demencial com “... 


\section{LITERATURA, PSICOPATOLOGIA}

movimentos desordenados e bizarrices, completo esquecimento da vida precedente, anulação da faculdade de perceber os objetos pelas impressões sensoriais, falta da faculdade do juízo, contínua agitação sem uma intencionalidade precisa, falta de consciência de si" (p. 6). Em 1845, Pathologie und Therapie der psychischen Krankheiten, de Wilhelm Griesinger (1845), se refere a dementia paralytica, cuja característica era a deterioração mental que poderia progredir até ao estado de apatia (Noll, 2009). Em 1863, Karl Ludwing Kahbaum, descreve com o nome de hebefrenia, o quadro de alienação mental que aparece na puberdade e se traduz por uma parada do desenvolvimento intelectual até a demência. Posteriormente ele descreve a catatonia, quadro de alienação acompanhado de rigidez muscular (Noll, 2009; Adityanjee et al., 1999). Em 1871, Eward Hecker reforça os conceitos da hebefrenia e das causas etiológicas (Noll, 2009; Adityanjee et al., 1999). Esse quadro de deterioração mental que se instalava na adolescência, ou no início da idade adulta, recebeu a denominação de demência precoce, por Bendict Augustim Morel, em 1853 (Adityanjee et al., 1999), recebendo a denominação de esquizofrenia, em 1911, quando Eugen Bleuler publica Dementia praecox ou o grupo das esquizofrenias (Adityanjee et al., 1999).

O Duplo é um romance que tem como personagem principal Yákov Pietróvitch Golyádkin, um funcionário burocrático de São Petersburgo, que apresenta a eclosão de um quadro psicótico (Dostoiévski , 2011).

Dostoiévski centraliza a história no mundo psíquico de Golyádkin, sem marcações claras de tempo, ora usando a voz no narrador e ora a voz da fala ou do pensamento de Golyádkin. A voz do narrador não delineia, claramente, o que é realidade e o que é devaneio ou delírio, o mundo interno do personagem é a realidade (Bakhtin, 2015). A obra é cheia de diálogos de Golyádkin consigo mesmo; em outras palavras, a vida interior do personagem é o centro da obra (Bakhtin, 2015). Tudo isto faz o leitor experimentar a angústia e o sofrimento da vivência psicótica.

O livro se inicia com Golyádkin despertando de uma noite de sono. Nesse dia, acorda animado, sentindo-se bem, satisfeito com sua própria imagem e com as economias que possuía. Vestiu a si mesmo e a seu criado com boas roupas e alugou uma carruagem para se dirigir para a festa de aniversário do conselheiro de Estado, Olsufi Ivanovitch. No caminho cruzou com dois colegas de trabalho e depois com o chefe de sua repartição, o que lhe despertou sentimentos de vergonha e dúvida. Repentinamente, resolve ir ao consultório do médico Cristian Ivánotich Rutenspitz. 


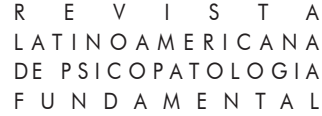

Golyádkin repetia diversas vezes no nome do médico, numa estereotipia verbal. "Cristian Ivanovitch, eu gosto de silêncio - disse o senhor Golyádkin, evidentemente procurando palavras para exprimir melhor seu pensamento no meu apartamento moramos só eu e Pietruchka... quero dizer, meu criado, Cristian Ivanovitch. Estou querendo dizer, Cristian Ivanovitch. Vivo no meu canto, e até onde me parece, não dependo de ninguém. Também dou meus passeios, Cristian Ivanovitch" (p. 22). E declara ao médico sua sensação persecutória "Eu tenho inimigos, Cristian Ivanovitch, tenho inimigos; tenho inimigos cruéis, que juraram me arruinar..., respondeu o senhor Golyádkin com ar amedrontado e entre murmúrios" (p. 26).

Golyádkin saiu do consultório médico em estado de agitação, visitando lojas, combinando compras de altos valores, de objetos diversos. “... enquanto isso sua inquietação aumentava cada vez mais. Percebia-se que ele se preparava para algo muito embaraçoso, para não dizer mais, murmurava de si para si, gesticulava com a mão direita, lançava olhares incessantes pelas janelas da carruagem" (p. 39).

"O senhor Golyádkin sabia, sentia e tinha plena convicção de que antes que chegasse em casa, forçosamente, ainda lhe aconteceria alguma coisa ruim, ... (p. 72). É possível observar, na narrativa de $O$ Duplo, que o personagem se encontrava em estado de inquietação, humor exaltado, sensação de perseguição, de que algo ruim iria lhe ocorrer, um mal-estar difuso. Esse quadro foi descrito em 1958, pelo psiquiatra alemão, Klaus Conrad, como a fase inicial da esquizofrenia, que denominou trema (Mishara, 2010; Santos \& Rodriguies, 1991; Ploog, 2002). Essa fase prodrômica da esquizofrenia tem como sintoma o "humor delirante", algo difuso, tensão, sensação de algo estranho no ar e sentimento de desconfiança.

A história atinge um ponto-chave com Golyádkin indo para a casa do chefe de Estado, onde não foi recebido. Ao ver seu chefe Andrei Filipovitch, e o sobrinho Vladimir Semeónovitch entrando na casa, fica muito perturbado, "desejou mentalmente meter-se debaixo do chão ou esconder-se com a carruagem até num buraco de ratos. Parecia-lhe que tudo o que havia na casa de Olsufi Ivanovitch o observava agora de todas as janelas. Sabia que morreria ali mesmo se olhasse para trás" (p. 42). Mas Golyádkin entra na casa pela porta dos fundos. Chegando à festa, se comporta de modo bizarro. Ele convida a filha de Olsufi para dançar e sua forma desajeitada e seus tropeços acabam por assustar a moça, que solta um grito, e ele é então retirado da casa.

Sai de lá correndo, numa noite de neve e chuva, em estado de grande agitação e sofrimento. "O senhor Golyádkin, fora de si, correu para o cais 


\section{LITERATURA, PSICOPATOLOGIA}

da Fontanka, ao lado da própria ponte Izmáilovski, fugindo dos inimigos, das perseguições, da saraivada de afrontas que recebera, dos gritos das velhas alarmadas, dos ais e uis das mulheres e dos olhares mortíferos de Andriêi Filíppovitch" (p. 63). Nesse estado de grande inquietação, ocorre o aparecimento de um duplo, ou sósia, duplicação do seu eu, que é chamado na narrativa de Golyádkin segundo. Esse outro tinha o mesmo nome e a mesma aparência física do Golyádkin primeiro, mas com uma personalidade diferente. "O senhor Golyádkin reconhecera por completo seu amigo noturno. O amigo noturno não era senão ele mesmo - o próprio senhor Golyádkin, outro senhor Golyádkin, mas absolutamente igual a ele —, era em suma, aquilo que se chama o seu duplo, em todos os sentidos..." (p. 74).

Após reconhecer seu duplo, Golyádkin chega a convidá-lo para ir à sua casa e trava uma relação amistosa com ele. Posteriormente, passa a encontrá-lo no trabalho e em outros lugares e a se sentir ridicularizado e perseguido por ele.

Essa crença pode ser considerada um sintoma psicopatológico, um tipo de delírio, que só foi descrito clinicamente, em 1978, pelo psiquiatra George Christodoulou. Ele denominou Síndrome de Duplos Subjetivos para o quadro cuja característica é a crença delirante de que outra pessoa foi fisicamente transformada em si próprio, mas com uma identidade psicológica diferente (Christodoulou, 1978).

Em 1923, Capgras e Reboul-Lachaux descreveram o caso de uma senhora, que acreditava que seu marido, filhos e vizinhos, além dela própria, haviam sido substituídos por sósias. A crença delirante de que pessoas da própria intimidade foram substituídas por duplos ou sósias, impostores que assumem os papéis das pessoas que personificam e se comportam de maneira idêntica, passou a ser denominada síndrome de Capgras (Signer, 1987) e foi o primeiro quadro do grupo das síndromes de falsa identificação delirante a ser publicado (Christodoulou, Margariti, Kontaxakis, \& Christodoulou, 2009).

Os quadros da síndrome de falsa identificação delirante são fenômenos psicopatológicos raros, que ocorrem nos casos de esquizofrenia, transtornos afetivos ou doenças orgânicas. Na classificação atual, pertencem a esse grupo a síndrome de Capgras, síndrome de Fregoli, síndrome da intermetamorfose, pluralização clonal do self e a síndrome de duplos subjetivos. São quadros que podem ocorrer simultaneamente, ou mudar de um para outro, e têm como característica comum o tema de O Duplo ou impostor (Feinberg \& Roane, 2005). Quando presentes no quadro de esquizofrenia, eles são 
geralmente precedidos por ideias paranoides e estão associados a alterações de linguagem, da sensopercepção, do pensamento e do comportamento.

Após o encontro de Golyádkin com seu duplo, a narrativa do livro prossegue tornando mais evidente a insanidade mental do personagem. Golyádkin teve um sonho no qual ele queria ser bem-visto por Andriéi Filíppovitch, mas sentia-se humilhado, desprestigiado, com a imagem denegrida diante dos outros, difamado e cheio de conflitos quanto ao seu caráter e moral. Nesse sonho

o senhor Golyádkin, por sua vez, se distinguia nos quesitos amabilidade e espiritualidade; que todos gostavam dele, até alguns de seus inimigos que ali se encontravam tinham passado a gostar dele, o que era muito agradável... imediatamente, num piscar de olhos o senhor Golyádkin segundo (o duplo) destruía com seu simples aparecimento todo o triunfo e toda a glória do senhor Golyádkin primeiro, pisoteava na lama o senhor Golyádkin primeiro e, por fim, demonstrava claramente que Golyádkin primeiro era ao mesmo tempo autêntico e absolutamente inautêntico, falsificado, que ele é que era o autêntico e, por último, Golyádkin primeiro não era nada daquilo que aparentava, porém, isso e mais aquilo, e, por conseguinte, não podia nem tinha o direito de pertencer a uma sociedade de pessoas bem-intencionadas e de bom-tom. (p. 155)

Nessa manhã delineou melhor a conspiração que havia contra ele. Foi para o trabalho no final do expediente. Lá sentiu-se desprezado e perseguido, percebeu que havia um descontentamento quanto a ele, que os colegas faziam "queixas e murmúrios" e o duplo zombava dele e fazia piadinhas. Apresentou alteração de linguagem, pensamento confuso, ideias desconexas e alterações psicomotoras. "Sentia-se ainda fraco e depauperado, que uma força especialíssima e estranha o conduzia, que em absoluto não era ele que caminhava e que suas pernas fraquejavam e se negavam a obedecer" (p. 181). Encontrou-se com o duplo num restaurante; sentindo-se ridicularizado teve a "intenção de estraçalhá-lo e assim ajustar definitivamente as contas com ele" (p. 189). "Na certa a desordem de seu uniforme, a inquietação incontida, a andança, ou melhor, a correria, a gesticulação com ambas as mãos e talvez algumas palavras enigmáticas lançadas ao vento e por descuido - certamente tudo isso deixou o senhor Golyádkin mal na opinião de todos os presentes" (p. 194). Deixou cair do bolso o frasco de remédio que o médico Cristian Ivanovitch Rutenspitz tinha lhe receitado, o vidro quebrou e lhe veio à mente “Então minha vida está em perigo!" (p. 196).

Por fim as ideias persecutórias se tornam marcantes. Quando o criado Pietruchka resolve deixar Golyádkin ele pensa "Isso é trabalho da alemã. É 


\section{LITERATURA, PSICOPATOLOGIA}

dela, daquela bruxa que parte tudo isso, que vem todo esse deus nos acuda" (p. 203). Pede ao sr. Olsufi Ivanovitch, numa conversa confusa, "que me proteja contra os inimigos" (p. 208). O livro termina com o Golyádkin sendo retirado da casa do Chefe de Estado pelo médico. Durante essa viagem, ele percebe que Cristian Ivanovitch não era ele mesmo, era outro, tinha sido substituído por um sósia, Cristian "terrível".

O tema do duplo ou duplicação do eu é encontrado na literatura desde a antiguidade, especialmente na mitologia e nos contos fantásticos. Pode ser encontrado em autores como Hoffman ( $O$ reflexo perdido), Adalberto Von Chamisso (A história maravilhosa de Peter Schlemihl), Nicolai Gogol (O nariz), Edgar Allan Poe (William Wilson), Oscar Wilde (O retrato de Dorian Gray) e Franz Kafka (A metamorfose). A temática foi largamente estudada, sendo interpretada como uma representação da dualidade humana ou uma tentativa de escapar da morte (Frank, 2008). A presença recorrente desse tema na literatura parece ter influenciado Dostoiévski na escolha de seu trabalho, mas $O$ Duplo difere das demais obras por introduzir no seu texto uma verdadeira descrição clínica.

Dostoiévski consegue descrever, claramente, a vivência delirante do sósia, possivelmente pelo encanto que tinha pelas doenças mentais, além de sua habilidade em observar e descrever fenômenos da vida. Tinha grande interesse em livros médicos e uma "fascinação mórbida por perturbações mentais", possivelmente, por ser portador de alguns sintomas (Frank, 2008). Associado a isso, Dostoiévski, em $O$ Duplo, utilizou sua aguçada habilidade de perceber e descrever a mente humana, de "entrar na pele de outra criatura" (Bianchi, 2003), de tal modo que avaliou o tema do duplo pela ótica da vivência interior e com isto, conseguiu a descrição psicopatológica prenunciadora do delírio de duplos subjetivos.

\section{Referências}

Adityanjee, Aderibigbe, Y. A., Theodoridis, D., \& Vieweg, W. V. R. (1999). Dementia praecox to schizophrenia: The first 100 years. Psychiatry and Clinical Neurosciences, 53(4), 437-448. http://doi.org/10.1046/j.1440-1819.1999.00584.x

Bakhtin, M. (2015). Problemas da poética de Dostoiévski (5 $5^{\mathrm{a}}$ ed.). Rio de Janeiro, RJ: Forence Universitária.

Bianchi, M. F. (2003). Dostoiévski e a crítica russa. Revista Magna, 8, 87-99. 


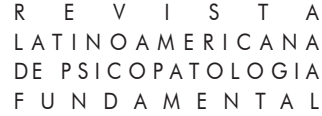

Christodoulou, G. N. (1978). Syndrome of subjective doubles. Am J Psychiatry, 135(2), 249-251. http://doi.org/10.1176/ajp.135.2.249

Christodoulou, G. N., Margariti, M., Kontaxakis, V. P., \& Christodoulou, N. G. (2009). The delusional misidentification syndromes: strange, fascinating, and instructive. Current Psychiatry Reports, 11(3), 185-189. Retrieved from: <http:// www.ncbi.nlm.nih.gov/pubmed/19470279>.

Dostoiévski, F. (2011). O Duplo. São Paulo, SP: Editora 34.

Feinberg, T. E., \& Roane, D. M. (2005). Delusional Misidentification. Psychiatr Clin $N$ Am, 28, 665-683. http://doi.org/10.1016/j.psc.2005.05.002.

Frank, J. (2008). Dostoiévski: As sementes da revolta (1821-1849). São Paulo, SP: Edusp.

Griesinger, W. (1845). Die Pathologie und Therapie der psychischen Krankheiten, für Aerzte und Studirende (1. Auflage). Stuttgart, Germany: Krabbe.

Iracy Doyle. (1955). Esquizofrenias. In Nosologia psiquiátrica (1 ${ }^{a}$ ed., pp. 162-289). Rio de Janeiro, RJ: Estab.Cordeiro de Farias.

Mishara, A. L. (2010). Klaus Conrad (1905-1961): Delusional Mood, Psychosis, and Beginning Schizophrenia. Schizophrenia Bulletin, 36(1), 9-13. http://doi. org $/ 10.1093 / \mathrm{schbul} / \mathrm{sbp} 144$.

602 Noll, R. (2009). Madness, psychosis, schizophrenia: A brief history. In The encyclopedia of schizophrenia and other psychotic disorders ( $3^{\mathrm{a}} \mathrm{ed} ., \mathrm{p}$. 409). New York: Facts on File.

Perissinotto, R. M. (2009). Dostoiévski em três novelas da juventude. Novos Estudos, $85,237-258$.

Pinel, P. (1809). Traité médico-philosophique sur l'aliénation mentale. (2a ed.). Paris, França: Brosson.

Ploog, D. W. (2002). Klaus Conrad (1905-1961). History of Psychiatry, 13(51 Pt 3), 339-60. Retrieved from: <http://www.ncbi.nlm.nih.gov/pubmed/12503578>.

Salvatore, P., Bhuvaneswar, C., Tohen, M., Khalsa, H.-M. K., Maggini, C., \& Baldessarini, R. J. (2014). Capgras' Syndrome in First-Episode Psychotic Disorders. Psychopathology, 47, 261-269. http://doi.org/10.1159/000357813

Santos, M. B., \& Rodriguies, V. A. (1991). Esquizofrenia-perspectivas de Conrad. Notas Didácticas.

Signer, S. F. (1987). Capgras' syndrome: the delusion of substitution. The Journal of Clinical Psychiatry, 48(4), 147-150. Retrieved from: <http://www.ncbi.nlm.nih. gov/pubmed/3558326>. 


\section{LITERATURA, PSICOPATOLOGIA}

\section{Resumos}

\section{(Psychopathology in Dostoyevsky's The Double)}

The Double addresses the topic of duplicity of self. It presents psychopathological descriptions of the syndrome of subjective doubles and of schizophrenia at a time in which these conditions had not yet been described. This paper situates the book in the history of psychiatry, highlighting the pioneering spirit of Fyodor Dostoyevsky, his way of approaching this topic, and how he managed to address it in a clinical way.

Key words: False delirium identification syndrome, syndrome of subjective doubles, schizophrenia, literature and medicine

(La psychopathologie dans Le Double par Dostoievski )

Le Double porte sur le thème de la duplicité du moi. Il contient des descriptions psychopathologiques du syndrome des doubles subjectifs et de la schizophrénie à une époque où ces troubles n'avaient pas encore été décrits. Cet article traite de l'œuvre littéraire dans l'histoire de la psychiatrie et souligne l'esprit pionnier de Fiodor Dostoïevski, sa façon de développer le thème et comment traiter la question de façon clinique.

Mots clés: Syndrome de la fausse identification délirante, syndrome du double subjectif, schizophrénie, littérature et médecine

(Psicopatología en El Doble de Dostoievski)

El Doble, de Dostoyevski aborda el tema de la duplicidad del yo. Trae, a la narrativa, descripciones psicopatológicas del sindrome de dobles subjetivos y de la esquizofrenia en una época en la que todavía no se habían descrito tales condiciones. En este artículo, se sitúa la obra literaria en la historia de la psiquiatría, resaltando el espiritu pionero de Fiódor Dostoyevski, su forma de narrar el tema y cómo logró abordar la cuestión de forma clínica.

Palavras clave: Síndrome de falsa identificación delirante, síndrome de los dobles subjetivos, esquizofrenia, literatura y medicina

(Psychopathologie in Dostoievskis Werk Der Doppelgänger)

Der Doppelgänger behandelt das Thema des doppelten Ichs. Das Werk enthält psychopathologische Beschreibungen des Syndroms des subjektiven Doppelgängers und der Schizophrenie zu einer Zeit, als diese Phänomene noch nicht beschrieben worden waren. Dieser Artikel ordnet das Werk in der Geschichte der Psychiatrie ein, unterstreicht den Pioniergeist von Fjodor Dostojewski, seine Art und Weise, das 


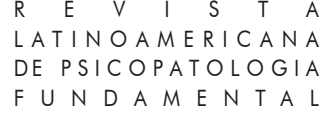

Thema wiederzugeben und wie er es schaffte, das Problem in klinischen Form zu behandeln.

Schlüsselwörter: Wahnhafte Missidentifikation, Syndrom des subjektiven

Doppelgängers, Schizophrenie, Literatur und Medizin

Citação/Citation: Zambaldi, C. F. (2017, setembro). Psicopatologia em O Duplo de Dostoiévski. Revista Latinoamericana de Psicopatologia Fundamental, 20(3), 595-604. http:// dx.doi.org/10.1590/1415-4714.2017v20n3p595.12

Editores do artigo/Editors: Vários.

Recebido/Received: 18.5.2017/ 5.18.2017 Aceito/Accepted: 10.7.2017 / 7.10.2017

Copyright: (C) 2009 Associação Universitária de Pesquisa em Psicopatologia Fundamental/ University Association for Research in Fundamental Psychopathology. Este é um artigo de livre acesso, que permite uso irrestrito, distribuição e reprodução em qualquer meio, desde que o autor e a fonte sejam citados / This is an open-access article, which permits unrestricted use, distribution, and reproduction in any medium, provided the original authors and sources are credited.

Financiamento/Funding: A autora declara não ter sido financiada ou apoiada / The author has no support or funding to report.

Conflito de interesses/Conflict of interest: A autora declara que não há conflito de interesses / The author has no conflict of interest to declare.

\section{Carla Fonseca Zambaldi}

Doutora em Neuropsiquiatria e Ciências do Comportamento; Psiquiatra da Universidade Federal de Pernambuco

Departamento de Neuropsiquiatra da Universidade Federal de Pernambuco Av. Prof. Moraes Rego, s/n. - Cidade Universitária 50670-901 Recife, PE, Br. carlafza@hotmail.com

This is an open-access article, which permits unrestricted use, distribution, the original authors and sources are credited. 